Title: Enhancing neural activity to drive respiratory plasticity following cervical spinal cord injury

\title{
Authors:
}

Kristiina M. Hormigo, Lyandysha V. Zholudeva, Victoria M. Spruance, Vitaliy Marchenko, MariePascale Cote, Stephane Vinit ${ }^{1}$, Simon Giszter, Tatiana Bezdudnaya, Michael A. Lane

\section{Authors addresses:}

Spinal Cord Research Center, Department of Neurobiology and Anatomy, College of Medicine, Drexel University, 2900 W Queen Lane, Philadelphia, PA, USA

1 Université de Versailles Saint-Quentin-en-Yvelines, INSERM U1179 End:icap, UFR des Sciences de la Santé - Simone Veil, Montigny-le-Bretonneux, France.

\section{${ }^{*}$ Correspondence to}

Michael A. Lane, Ph.D.

Spinal Cord Research Center

Department of Neurobiology \& Anatomy

Drexel University

2900 W Queen Lane

Philadelphia, PA, 19129

mlane.neuro@gmail.com

Phone: $+1-215-991-8890$

\section{Keywords:}

Spinal cord injury, neuroplasticity, respiration, phrenic, spinal interneuron 


\begin{abstract}
Cervical spinal cord injury (SCl) results in permanent life-altering sensorimotor deficits, among which impaired breathing is one of the most devastating and life-threatening. While clinical and experimental research has revealed that some spontaneous respiratory improvement (functional plasticity) can occur post-SCI, the extent of the recovery is limited and significant deficits persist. Thus, increasing effort is being made to develop therapies that harness and enhance this neuroplastic potential to optimize long-term recovery of breathing in injured individuals. One strategy with demonstrated therapeutic potential is the use of treatments that increase neural and muscular activity (e.g. locomotor training, neural and muscular stimulation) and promote plasticity. With a focus on respiratory function post-SCl, this review will discuss advances in the use of neural interfacing strategies and activity-based treatments, and highlights some recent results from our own research.
\end{abstract}




\section{INTRODUCTION}

The formation and retention of functionally relevant neuronal connections during development is driven in part by motor and sensory activity. Increased and/or repetitive activity in mature pathways strengthens existing neuronal circuits (increasing synaptic and dendritic growth), refines and prunes irrelevant connectivity through synaptic competition, and can promote the recruitment of additional neurons into these pathways while preserving selectivity. Accordingly, these neuroplastic changes can be harnessed for therapeutic gain. Treatments designed to stimulate neural activity can contribute to the formation of new neural pathways and repair of those that are damaged, ultimately resulting in improved function following spinal cord injury (SCl). Strategies to drive neural activity can be separated into those using electrical stimuli ('neural interfaces' (NI's): functional electrical stimulation, epidural stimulation, transcranial magnetic stimulation) and physical stimuli ('activity-based therapies' (ABTs): rehabilitation, locomotor training). NIs and ABTs may be structured to either engage local circuits and musculoskeletal subsystems (e.g. a specific muscle and reflex) targeted in the therapy, or to engage broader system function (e.g. locomotion as a whole). Both approaches are becoming widely recognized as effective, clinically-viable means of reactivating neural circuitry that might otherwise remain inactive following $\mathrm{SCl}$. For instance, electrical stimulation of the spinal cord caudal to a $\mathrm{SCl}$ (e.g. using epidural stimulation and intraspinal microstimulation) can restore sufficient activity to denervated spinal motor networks en masse to evoke not only simple tasks such as stance, but also more complex patterned limb movements (Bamford and Mushahwar, 2011; Tator et al., 2012), or to regulate specific synergies and phases of locomotion (Giszter, 2015; Wenger et al., 2016). With some parallels to electrical stimulation, physically increasing activity with exercise or rehabilitation also activates neural circuits in a localized or more general fashion. Persistence of this physical training strengthens the muscles being used, stimulates afferent feedback and drives contextual neural plasticity. For example, treadmill training can harness beneficial neuroplastic changes to promote lasting functional improvement in people with SCI (Harkema, 2001). More recently combinations of Nls and ABTs (e.g. epidural stimulation and locomotor training) have been shown to act synergistically for further enhancement of function (Hsieh and Giszter, 2011).

While historically the focus has been on improving locomotor recovery, there is growing appreciation for how stimulating neural activity can be used to treat non-locomotor impairments (bladder dysfunction, pain, spasticity, and respiration). Autonomic and segmental sensory motor function is likely integrated at the circuit level, but little effort has been made to investigate these interactions. General system effects of neural motor activity are likely more pervasive than they 
were previously considered. Building upon recent clinical findings and ongoing experimental studies, the present review discusses how strategies for stimulating neural activity can be used therapeutically to enhance respiratory function following cervical SCI.

\section{RESPIRATION POST-SCI}

Motoneurons innervating respiratory muscles are distributed throughout the cervical, thoracic and lumbar spinal cord (innervating the diaphragm, intercostals and abdominals, respectively) (Lane, 2011). Thus, SCI at any of these levels can affect respiratory function. Injuries at thoracic and lumbar levels can compromise the motor pathways controlling the intercostal and abdominal muscles. While thoracic and lumbar level injuries have little impact on inspiratory function (largely mediated by the phrenic motor system and diaphragm), they can produce deficits in respiratory-related behaviors (e.g. sneezing, coughing). Furthermore, impaired airway clearance can contribute to life-threatening secondary respiratory infections (Baydur and Sassoon, 2010).

The most severe respiratory deficits arise following cervical $\mathrm{SCl}$, which not only partially or completely denervates respiratory circuitry at thoracic and lumbar spinal levels, but directly compromises the phrenic motor circuitry. Spinal phrenic motoneurons innervate the diaphragm, which is the most important respiratory muscle. Thus, injuries compromising phrenic motor function result in diaphragm paralysis/paresis, and typically necessitate assisted ventilation. Furthermore, cervical SCI denervates more caudal respiratory circuitry resulting in a combined inspiratory and expiratory dysfunction, impairing defensive respiratory-related behaviors (e.g. cough), and thereby increasing the risk of secondary complications (e.g. infection).

Despite these devastating outcomes, extensive research has shown some potential for respiratory plasticity and spontaneous functional recovery following cervical SCI. While the amount of recovery attributable to plasticity is limited, several studies have shown that onset and extent of plasticity can be therapeutically enhanced. Ongoing research is identifying new therapeutic targets that will promote respiratory plasticity and lasting recovery of breathing postSCl.

\section{PLASTICITY AFTER CERVICAL SCI}

For the purpose of this review neuroplasticity can be defined as the ability of the nervous system to make anatomical and functional changes that lead to persistent alterations in sensory-motor function. These changes can be mediated by a range of factors, such as an experience (e.g. learning), persistent activity (e.g. training), or injury (e.g. SCI). Furthermore, 
this plasticity can occur 'spontaneously' (without external interference) following traumatic SCI and/or following therapeutic intervention (driven by external influences). An important goal for $\mathrm{SCl}$ treatments is that they either; i) do not impair spontaneously occurring, beneficial plasticity, ii) limit any detrimental aspects of plasticity (e.g. spontaneously occurring pain), or even more preferably, iii) act synergistically to enhance intrinsic neuroplasticity and optimize the extent of lasting functional improvement.

Following SCl, anatomical plasticity (e.g. reorganization of neuronal connections, activation of spared latent pathways) can lead to functional plasticity (e.g. restoration of activity in damaged pathways, increased activity in spared pathways to compensate for damage, synaptic strengthening), and vice-versa. While the present review focuses on neuroplastic changes within the spinal cord post-injury, it should also be noted that plasticity from the peripheral nervous system (Mantilla and Sieck, 2009; Nicaise et al., 2012b) to supraspinal circuitry (Golder et al., 2001; Goshgarian, 2009) can occur post-SCI and may affect functional outcome. Even a localized event (e.g. SCl) can result in plasticity through the brain, brainstem, spinal cord, peripheral nerves and muscle (Bezdudnaya et al., 2014; Oza and Giszter, 2014, 2015; Raineteau and Schwab, 2001). Another important consideration is that neuroplastic changes do not always translate to functional improvements and may even result in erroneous and detrimental (maladaptive) functions (e.g. pain, spasticity) (Byl 2004; Norenberg 2004; Dashtipour et al. 2007). With that in mind, the timing and 'dose' of any treatment must be carefully assessed to limit maladaptive effects and optimize repair and recovery.

Evidence for functional respiratory plasticity was first demonstrated over a century ago using a lateral $\mathrm{C} 2$ hemisection $(\mathrm{C} 2 \mathrm{Hx}$ ) (Porter, 1895), which has since become the most frequently used model of respiratory dysfunction and plasticity following SCI (Goshgarian, 2003a; Hoh et al., 2013; Vinit and Kastner, 2009b; Warren and Alilain, 2014). This type of injury compromises direct (monosynaptic) projections from the ventral respiratory column in the medulla to ipsilateral phrenic motoneurons (Ellenberger and Feldman, 1988; Ellenberger et al., 1990; Keomani et al., 2014; Lane et al., 2009b; Lane et al., 2008; Vinit and Kastner, 2009a), and results in an ipsilateral hemidiaphragm paralysis (Figure 1). Despite the extent of injury, acute partial recovery of phrenic and hemidiaphragm activity after $\mathrm{C} 2 \mathrm{Hx}$ can be accomplished by a subsequent contralateral phrenicotomy (Goshgarian, 2003a; Porter, 1895) or by inducing a respiratory stress such as asphyxia, hypoxia or hypercapnia (Golder and Mitchell, 2005; Lewis and Brookhart, 1951). This type of post-injury plasticity - known as the "cross-phrenic phenomenon" (CPP) - is attributed to activation of contralateral (spared), normally latent, 
bulbospinal pathways that cross the spinal midline below the injury (Figure 1A) (Goshgarian et al., 1991; Moreno et al., 1992). While not normally active, these pathways become active post$\mathrm{C} 2 \mathrm{Hx}$ following a respiratory challenge or stress (Goshgarian, 2003b; O'Hara and Goshgarian, 1991; Vinit et al., 2006), and removing the respiratory challenge abolishes the described recovery. Spontaneous, long-lasting recovery of phrenic activity, albeit to a limited extent, has also been observed in chronic $\mathrm{C} 2 \mathrm{Hx}$ animals and occurs within weeks to months following injury (Figure 1B) (Fuller et al., 2008; Nantwi et al., 1999). There is some suggestion that this spontaneous plasticity, or "spontaneous cross-phrenic phenomenon", may be distinct from the pathways described for the crossed-phrenic phenomenon and involve axonal sprouting, rerouting (Darlot et al., 2012; Vinit et al., 2005; Vinit and Kastner, 2009b) and the formation of new polysynaptic connections with phrenic motoneurons via cervical spinal interneurons (Darlot et al., 2012; Lane et al., 2009c; Lane et al., 2008; Sandhu et al., 2009). The extent of recovered phrenic motor function, however, remains limited (Fuller et al., 2008; Lane et al., 2009a; Vinit et al., 2006) and significant deficits in breathing persist for months post-injury (Fuller et al., 2008; see also Figure 1B).

A growing number of studies have begun to assess respiratory function using more clinically comparable contusion injury models (Figure 2). With a primary focus again on the phrenic motor system, these studies have also begun to demonstrate the capacity for spontaneous respiratory plasticity. El-Bohy, Reier and Goshgarian were the first to show that lateral or midline cervical contusion resulted in reduced phrenic motor output, and an attenuated phrenic motor response to respiratory challenge (Figure 2B) (El-Bohy et al., 1998). Using plethysmography, Choi et al. (2005) subsequently showed that ventilatory patterns were altered acutely following a lateral contusion - exhibiting rapid, shallow patterns of breathing (analogous to that seen following $\mathrm{C} 2 \mathrm{Hx}$ ), but there was a progressive recovery toward a more normal breathing behavior weeks post-injury. One study did show greater recovery, following only minimal functional deficit that was associated with a more mild contusive injury (Alvarez-Argote et al., 2016). More recently, we (Lane et al., 2012) and others (Awad et al., 2013; Baussart et al., 2006; Golder et al., 2011; Nicaise et al., 2013; Nicaise et al., 2012a; Nicaise et al., 2012b) have confirmed these original findings, providing some evidence for phrenic and ventilatory plasticity following moderate to severe $\mathrm{SCl}$, but as is seen in the $\mathrm{C} 2 \mathrm{Hx}$ model the extent of recovery is limited and significant deficits persist.

\section{THERAPEUTICALLY SHAPING RESPIRATORY NEUROPLASTICITY}


Substantial efforts have been made to develop treatments capable of enhancing recovery of phrenic motor function and diaphragm activity. In the present review, these treatments are grouped into therapies that are designed to drive this activity via electrical (neural interfacing) or non-electrical stimulation (activity-based therapies) in people with SCl. The primary therapeutic goal of neural stimulation post-SCI is to activate otherwise silenced/paralyzed circuitry and muscles. When applied under the right conditions the beneficial effects can also persist after termination of treatment (Mercier et al., 2016; Posluszny et al., 2014). Such therapies, summarized in Figure 3, are designed to stimulate neural activity via electrical stimuli applied to the periphery (functional electrical stimulation (A)), spinal cord (epidural stimulation (B) or intraspinal microstimulation (C), and transcranial magnetic stimulation (D)) or supraspinal regions (transcranial magnetic stimulation and deep brain stimulation), or via physical stimuli (locomotor training $(F)$ and respiratory rehabilitation $(E)$ ). Evidence for efficacy of both electrical and non-electrical strategies have come from clinical and pre-clinical studies. Each strategy activates neural circuits, amplifying beneficial neuroplastic changes that can promote lasting functional improvements post-SCI.

\section{Neural Interfacing and Respiratory Neuroplasticity}

Rapid advances in bioengineering and brain-computer interface technology have driven forward the clinical use of operative neuromodulation (electrically or chemically altering synaptic transmission via implantable devices). A wide variety of devices now are being surgically implanted to interface with the nervous system for the treatment of motor (e.g. diaphragm pacing, epidural stimulation, deep brain stimulation for movement disorders) and sensory (e.g. retinal and cochlear implants) deficits. These devices also range from externally controlled open-loop devices to self-regulating closed-loop interfaces. Open-loop devices, such as diaphragm pacers that can be used to treat respiratory dysfunction (Onders, 2012; Onders et al., 2007; Onders et al., 2010; Posluszny et al., 2014; Tedde et al., 2012), generate electrical stimulation based on an exogenous signal (e.g. a pre-programmed external controller). Closedloop devices record and amplify signals from sensors (e.g. position sensor, muscle contraction sensors) implanted within the recipient, and use the recorded (endogenous) signal for stimulation. In this case, voluntary contraction or movement of non-paralyzed muscle/circuity could be used to trigger stimulation of paralyzed pathways or muscles.

As this review highlights, these are just some of the neural interfacing strategies that can be used to improve respiratory function post-SCl. Furthermore, growing use of both open- and closed-loop strategies has begun to reveal that the benefits of stimulation are not limited to 
merely treating a deficit. Long-term, repeated stimulation may actually drive neuroplasticity, contribute to rewiring of neural circuitry, and overall greater recovery of impaired function.

\section{Functional Electrical Stimulation}

Functional electrical stimulation (FES) is the direct stimulation of muscles or peripheral nerves which can provide sufficient efferent activity to elicit muscle contraction in otherwise paralyzed muscles. FES has been applied to produce both isometric muscle contractions (which are conditioning) and contractions against resistance (exercise), thus counteracting or limiting disuse atrophy (Baldi et al., 1998; Giangregorio and McCartney, 2006). Improved fatigue resistance, increased muscle mass and maximal force can be seen within a few months of FES therapy. Muscle conditioning and exercise often are a necessary step for regaining muscle mass before applying any additional therapies directed at recovery of lost function. The management of post-SCI respiratory dysfunction using open-loop muscle/nerve FES (e.g. diaphragm pacing (Gonzalez-Bermejo et al., 2015; Onders, 2012; Onders et al., 2014; Posluszny et al., 2014)), represents a significant improvement over alternative assistedventilation strategies. Ongoing work in this area has revealed that it not only maintains ventilation, but may also contribute to plasticity and lasting functional recovery (Posluszny et al., 2014).

The use of FES treatments for respiratory dysfunction post-SCI has focused on the phrenic motor system, likely due to the primary role the phrenic system has in maintaining ventilation (Lane, 2011). While non-ventilatory respiratory-related functions (e.g. expiratory behaviors such as cough) are extremely important to individuals with spinal cord injury, the scope of the present review is also focused to ventilatory functions. Phrenic nerve stimulation and diaphragm pacing (Figure $3 \mathrm{Ai}$ ) are FES strategies which effectively maintain ventilation in people with cervical SCI. Aside from significantly improving the quality of life for people requiring assisted ventilation (e.g. tracheal tubes are not required), restoring muscle activity attenuates rapid disuse atrophy. Disuse atrophy of respiratory muscles may occur far more quickly than in non-respiratory muscles, with muscular changes seen within hours of positive pressure mechanical ventilation (Powers et al., 2009). Patients that have had long-term mechanical ventilation and experienced diaphragm atrophy require muscle reconditioning, which can in fact be achieved with muscle pacing (Dalal and DiMarco, 2014; DiMarco et al., 2005a). Thus, these strategies represent a significant improvement in the management of respiratory dysfunction post-SCI (Alshekhlee et al., 2008; Creasey et al., 2004; Dalal and DiMarco, 2014; DiMarco, 
2001, 2005, 2009; DiMarco et al., 2005a; DiMarco et al., 2002; DiMarco et al., 2005b; Ho et al., 2014; Onders, 2012; Onders et al., 2007; Onders et al., 2011; Tedde et al., 2012).

Initial studies in the 1970s revealed that phrenic nerve stimulation could eliminate the need for mechanical ventilation, greatly increasing an injured individual's independence and quality of life. However, the implantation of the stimulating electrodes requires a thoracotomy and surgical manipulation of the phrenic nerves (in close approximation to the brachial plexus), posing a risk of nerve damage, and thereby exacerbating deficits and morbidity. Furthermore, as pacers for phrenic nerve stimulation are placed within the neck, they fail to stimulate the accessory phrenic nerve which merges with the main trunk of the phrenic nerve within the thoracic cavity. In contrast, direct stimulation of the diaphragm at the motor end point with diaphragm pacing avoids these risks.

Diaphragm pacing represents a viable alternative to mechanical ventilation, significantly improving quality of life for injured individuals (Dalal and DiMarco 2014). This procedure involves visualizing the abdominal surface of the diaphragm via laproscopy, electrophysiologically mapping the muscle to identify the primary motor point for optimal contraction, and surgical implantation of stimulating electrodes at that site. Clinical studies have shown that diaphragm pacing not only reduces or eliminates the need for mechanical ventilation (Dalal and DiMarco, 2014; DiMarco, 2005), but it can also promote progressive recovery of independent respiration (Bass et al., 2005; Posluszny et al., 2014). While it has been suggested that diaphragm pacing may induce neuroplastic changes in the respiratory system and facilitate recovery in SCl patients (Onders, 2012), the mechanisms involved in this recovery remain unknown.

Unfortunately, not all injured individuals are eligible for phrenic nerve stimulation or diaphragm pacing as intact phrenic motoneurons (distributed C3-C5) and phrenic nerves are required in order to elicit muscle contraction (DiMarco et al., 2005a; Gonzalez-Bermejo et al., 2015). Injuries directly compromising the C3-5 spinal cord or resulting in root avulsion/nerve damage typically result in a paralyzed diaphragm that cannot be stimulated. Thus, treatments are typically limited to those people with respiratory deficits that arise from injury above C3 (Dalal and DiMarco 2014). However, there is some evidence to suggest that if there is partial phrenic sparing contralateral to an asymmetric (lateralized) $\mathrm{SCl}$, then combined contralateral phrenic and bilateral intercostal pacing may yield similar functional benefits (DiMarco et al., 2005b). Moreover, effectiveness of diaphragm pacing may be time dependent and only acute post-injury patients may benefit from this intervention (Jarosz et al., 2012). For these reasons, additional reverse-translation studies in animal models are needed to explore mechanisms 
contributing to diaphragm stimulation and its effects on neuroplasticity, muscle preservation, improvements in general respiration as well as ways to improve existing pacing techniques. Given some of these caveats, DiMarco et al. (DiMarco and Kowalski, 2010, 2011; DiMarco et al., 1994) explored whether stimulation of intercostal muscles via spinal cord stimulation (see below) could achieve similar therapeutic efficacy.

The focus of most FES strategies for respiratory systems has been on the restoration of inspiratory function to improve ventilation. However, electrical stimulation of abdominal muscles can also assist expiratory functions (Bell et al., 2007; McBain et al., 2013, 2015), and thus may be a viable means of treating these deficits in injured individuals. Abdominal muscle activation for assisted expiration has even been achieved using non-invasive high-frequency magnetic stimulation, surface muscle stimulation and the more invasive strategy of stimulating the ventral roots of the lower thoracic spinal cord (reviewed in DiMarco 2005).

\section{Stimulating non-respiratory muscles to enhance respiratory function}

The integration of breathing with motor function and vice versa is well known. Maximum efforts involve breathing coordination, exemplified by forced expiratory event during physical exertion (e.g. weight lifter's grunt during a lift). Alternatively, respiration efficiency can benefit from phase-locking to locomotion or other motor activity. While the respiratory muscles/nerves remain a logical therapeutic target for FES to enhance respiratory function, an often underappreciated fact is that stimulation of non-respiratory muscles may also enhance activity within respiratory systems (Figure 3Aii). The integration of respiratory and non-respiratory (e.g. locomotor pathways) provides an anatomical and functional substrate that can be harnessed to modulate respiratory function post-injury (Isaev et al., 2004; Morin and Viala, 2002; Palisses et al., 1988; Persegol et al., 1993; Viala et al., 1987). Experimental studies have shown that stimulation of peripheral nerves innervating either the upper or lower limbs, as well limb muscles themselves, can rapidly induce changes in respiration (D'Orangeville et al., 2013; Iscoe and Polosa, 1976; McCloskey and Mitchell, 1972; Persegol et al., 1993; Potts et al., 2005; Tibes, 1977; Waldrop et al., 1986b). The two main effects that have been observed during peripheral nerve stimulation are respiratory rhythm entrainment (Iscoe and Polosa, 1976; Morin and Viala, 2002; Potts et al., 2005) and increased phrenic output (Persegol et al., 1993; Tibes, 1977; Waldrop et al., 1986b). More specifically, a number of studies have demonstrated that activation of group III and IV muscle afferents may be primarily responsible for the effects seen in the respiratory output (Hill et al., 1996; Mateika and Duffin, 1995; Tibes, 1977). In addition, coupling between respiratory and locomotor systems at the spinal and supraspinal levels may contribute 
to observed changes in respiration. For example, in a preliminary study we observed that stimulation of hind limb (tibialis posterior extensor muscle) of an anesthetized, vagotomized adult female rat for less than one minute can be used to entrain the animal's respiratory rhythm in a 2:1 ratio of stimulus to phrenic burst (Figure 4). Thus, stimulation of non-respiratory muscles may represent a viable means of activating respiratory circuits (as shown in Figure 3Aii). While these experiments were conducted in spinal intact animals, the results highlight how primary afferent feedback can modulate spinal respiratory activity (Gariepy et al., 2012; Gariepy et al., 2010; Morin and Viala, 2002). In fact, more recent experiments have confirmed that stimulation of muscles in the upper extremities, and thus associated primary afferents, can restore phrenic motor output to an otherwise silent phrenic motor pool caudal to a C2 hemisection injury (Bezdudnaya et al., 2015).

A common theme amongst therapeutic effects of all FES strategies within the central nervous system discussed above is that the stimulation of primary afferents to modulate spinal neuron activity appears to play an important role in spinal plasticity.

\section{Spinal stimulation to enhance respiratory plasticity and recovery}

Given the importance of primary afferent stimulation in the reported benefits of FES strategies, it is not surprising that several studies have assessed whether direct stimulation of afferent fibers in the spinal cord (within the dorsal roots) can achieve similar or enhanced therapeutic effects. Early attempts to treat pain by peripheral nerve stimulation encountered variability in outcome, and prompted a neurosurgeon in the late 60s - Clyde Norman Shealy - to speculate that direct stimulation of the spinal cord may be equally if not more effective (Shealy et al., 1967). Through assessing optimal electrode placement, and altering stimulation intensity and frequency, however, it became clear that patterned spinal motor activity could also be activated by epidural spinal stimulation (Dimitrijevic and Faganel, 1980; Sherwood et al., 1980). There is now rapidly growing appreciation for the fact that spinal stimulation (e.g. epidural or intraspinal stimulation) can be used to directly target spinal neurons caudal to injury, 'priming' the circuitry, increasing neuronal excitability and driving functional locomotor plasticity and recovery (Edgerton et al., 2008; Harkema et al., 2011; Ichiyama et al., 2008; Lavrov et al., 2006), as reviewed in detail (Edgerton and Harkema, 2011; Tator et al., 2012).

The use of epidural stimulation (Figure 3B) for treating respiratory dysfunction has focused primarily on driving intercostal muscle activity (DiMarco et al., 1987; DiMarco and Kowalski, 2010, 2011, 2015; DiMarco et al., 2005b). Using a ventrally placed stimulating electrode in the upper thoracic spinal cord, DiMarco and Kowalski have shown improved 
intercostal and diaphragm activity (DiMarco and Kowalski, 2010; DiMarco et al., 2005b; Kowalski et al., 2013). Epidural stimulation of the ventral surface of the intact upper thoracic spinal cord promoted sufficient intercostal muscle activity to contribute to ventilation, even following a bilateral phrenicotomy (DiMarco and Kowalski, 2010). In addition, an initial clinical trial confirmed that stimulation could maintain limited ventilation, albeit for short periods of time (DiMarco et al., 2005b). The authors state that it is likely that this approach directly stimulates ventral roots, rather than intraspinal circuity, thus referring to the technique as 'ventral root stimulation' (VRS) (DiMarco et al., 1994). While VRS alone resulted in only modest improved in ventilation, the combination of VRS and diaphragm pacing increased therapeutic efficacy (DiMarco et al., 2005b). Although people with compromised phrenic circuitry are ineligible for diaphragm pacing, combined diaphragm pacing and VRS can maintain ventilation even following partial compromise of the phrenic motor system.

More recent studies by DiMarco et al (DiMarco and Kowalski, 2009, 2011, 2013, 2015) have revealed greater therapeutic efficacy with high-frequency epidural stimulation, with which the goal is to stimulate spinal pathways (Dimarco and Kowalski, 2013). This high-frequency $(300 \mathrm{~Hz})$ spinal cord stimulation can drive simultaneous activation of both diaphragm and intercostal muscles following complete high- (C1-2), mid- (C4) and low- (C8) cervical transection. Furthermore, long-term ventilation could be maintained at low stimulation amplitudes ( 0.5-1.0mA) (DiMarco and Kowalski, 2009). The authors suggest that highfrequency spinal cord stimulation stimulates spared spinal pathways resulting in a more 'physiological' activation of inspiratory muscles. As shown in Figure 5, preliminary studies using a similar high-frequency spinal cord stimulation strategy demonstrate that stimulation of the midcervical (C4) ventral spinal cord (60 $\mu \mathrm{A}, 0.2 \mathrm{~ms}$ pulse, $200 \mathrm{~Hz}, 0.33 \mathrm{~s}$ pulse train duration) with two teflon-coated silver wires (0.01" bare and 0.013" coated with 1mm un-insulated tips, AMSystems) was sufficient to activate respiratory muscles and maintain ventilation following a complete $\mathrm{C} 1$ transection in unanesthetized decerebrate rats. Despite the therapeutic potential for spinal cord stimulation in improving respiratory function post-SCl, these strategies remain in pre-clinical testing. An important advantage spinal cord stimulation has over FES strategies is that physiological activation of spinal circuitry can stimulate coordinated activity in multiple respiratory systems (e.g. phrenic and intercostal). In addition, the risk of muscle fatigue inherent to FES and its non-physiological recruitment order is avoided or reduced. Notable caveats of epidural stimulation compared with FES, however, are that i) the surgical implantation of stimulating electrodes is far more invasive and ii) stimulation can also elicit unintended activation of non-respiratory muscles. 
This latter issue (extraneous effects of epidural spinal cord stimulation) may arise from the relatively large area stimulated with epidural electrodes. Such wide spread stimulation of spinal substrates will activate both intended and unintended circuitry. In addition, epidural stimulation has primarily been used to activate axons of passage at the site of stimulation, rather than deeper grey matter structures due to the physiological properties of stimulation (Cuellar et al., 2013; Ranck, 1975). More precise activation of spinal neurons can be achieved via implantation of intraspinal microwires. In recent years, intraspinal microstimulation (see Figure $3 \mathrm{C}$ ) has been shown to effectively promote some recovery of both lower (Bamford and Mushahwar, 2011; Bamford et al., 2011; Bamford et al., 2010) and upper (Kasten et al., 2013; Moritz et al., 2007; Sunshine et al., 2013) extremities post-SCI. Intraspinal microstimulation has now also been used to activate respiratory circuitry caudal to SCI (Mercier et al., 2016). Stimulating the C4 ventral grey matter via a single tungsten microwire $(100 \mathrm{~Hz})$, Mercier et al. (2016) demonstrated restoration of activity to the paralyzed hemidiaphragm acutely following $\mathrm{C} 2 \mathrm{Hx}$, that persisted even once stimulation ceased. The authors also employed a closed-loop paradigm, using recorded genioglossus activity as the trigger for intraspinal microstimulation , enhancing the physiological relevance of this strategy further. While activation of non-respiratory muscles was also observed in this initial study, modification of stimulating wires and surgical placement in future work will likely reduce these unwanted effects and improve stimulation resolution. Improved electrode technologies, which are under investigation, are needed for intraspinal microstimulation to provide long term stability and site precision in clinical settings.

\section{Supraspinal Electrical Stimulation}

Given that the majority of SCls are anatomically incomplete, another strategy for activating spared neural substrates is the stimulation of supraspinal neurons. This can be achieved invasively with deep brain stimulation or non-invasively with transcranial magnetic stimulation (TMS), transcranial direct current stimulation, and its variants. While TMS (Figure 3D) has been used as a diagnostic tool (to assess functional connectivity between the motor cortex and spinal neurons), it is gaining popularity as a means of therapeutically enhancing neural activity and plasticity. This technique utilizes a brief, highly intense magnetic field applied to cortical and sub-cortical areas to elicit volleys of action potentials which propagate from supraspinal levels to their muscular targets. A number of clinical studies have demonstrated TMS to be an effective way of generating diaphragmatic motor evoked potentials (Davey et al., 1996; Khedr and Trakhan, 2001; Lissens and Vanderstraeten, 1996) and may be a safe, non-invasive, and readily usable strategy for neuromodulation and treatment of respiratory dysfunction post-SCI 
(Vinit et al., 2016; Vinit et al., 2014). While supraspinal neuromodulation (e.g. repetitive TMS) following cervical $\mathrm{SCI}$ could contribute to functional respiratory recovery, experimental studies have been lacking. The size of the magnetic coil required for stimulation has been a limiting factor in assessing TMS in small animal models. This issue has been partially addressed by shielding the animal from the coil. Capitalizing on this strategy, we recently demonstrated the feasibility of using TMS by recording specific diaphragmatic motor evoked potentials in the adult rat (Vinit et al 2014). TMS can also be used to assess excitability and plasticity of phrenic motoneurons post-SCI via non-invasively accessing supraspinal respiratory centers. For example, we have demonstrated early functional neuroplasticity with TMS in the absence of spontaneous functional diaphragm activity on the injured side in a C2Hx rat (Vinit et al. 2016). More specifically, TMS was used to stimulate supraspinal structures, inducing action potential volleys which may travel via spared bulbospinal pathways (contralateral to injury), eliciting diaphragmatic motor evoked potentials on the injured, paralyzed, side of the diaphragm. Although preliminary, the results of these experiments lay the foundation for exploring the therapeutic potential of this unique, non-invasive technique in preclinical animal models of respiratory injury or disease.

\section{NON-ELECTRICAL NEURAL STIMULATION}

Activity-based therapies (ABTs) have extensively shown to promote neuroplasticity and improve function post-SCI in several sensory and motor systems, in a range of neurological disorders (stroke, brain injury, SCI). For example, there is extensive evidence for locomotor training having beneficial effects on plasticity and locomotor function following SCI (Galea et al., 2013; Hajela et al., 2013; Hillen et al., 2013; Hubli and Dietz, 2013; Martinez et al., 2013; Morawietz and Moffat, 2013; Singh et al., 2011a; Singh et al., 2011b) and locomotor training has proven to be beneficial for people with a range of SCls (different spinal levels and severities). Functional improvements have also been seen across multiple motor and sensory systems using a range of different training strategies (see Houle and Cote (2013) for discussion). ABTs and training paradigms that enhance respiratory function, have also been adapted for conditioning and strengthening of respiratory muscles (Hammond et al., 1999; Sapienza and Wheeler, 2006). Such training may enable individuals that are dependent on assisted-ventilation to recover sustained voluntary control of breathing, dramatically improving quality of life. Such respiratory training paradigms include the use of intermittent hypoxia and merit exploration and discussion within the field. 
Respiratory Training and Intermittent Hypoxia $(I H)$

Respiratory training can be divided into inspiratory and expiratory training strategies, which are chosen based on exhibited deficits (Bolser et al., 2009; Laciuga et al., 2014; Martin et al., 2011; Sapienza et al., 2011). Thus, people with cervical SCI are candidates for both inspiratory and expiratory training. Respiratory muscle training can be achieved by having an individual breathe through a tube in which airflow can be impeded (intake or outflow) (Sapienza and Wheeler, 2006) Figure $3 \mathrm{Ei})$. Thus, respiratory muscles have to work harder against the resistance encountered with each breath. The benefits of resistance training can be seen in improved ventilation under normal (eupneic) conditions, and other respiratory behaviors such as sneezing, sniffing or coughing. Furthermore, it represents a viable means of strengthening respiratory muscles to facilitate weaning people from assisted ventilation. However, very little is known about how these training protocols contribute to plasticity. While substantial clinical research has been conducted in this area, reverse-translating these types of training paradigms to animals models, although logistically difficult, will enable greater assessment of the underpinnings.

While training devices offer an effective method for resistance training in respiratory muscles, altering inhaled oxygen and carbon dioxide levels offer an alternative means of increasing neural drive and respiratory muscle activity (Figure 3Eii). Oxygen and carbon dioxide act on peripheral and central chemoreceptors to stimulate respiratory drive at the brainstem level. It is possible that spinal circuitry is stimulated by alterations in blood gas, but less is known. Repeated (intermittent) exposures to decreased inhaled oxygen (hypoxia) (or 'intermittent hypoxia' $(\mathrm{IH})$ ) provides a non-invasive means of amplifying spinal respiratory plasticity (Mitchell and Johnson, 2003; Wilkerson and Mitchell, 2009) which can be used to enhance diaphragm recovery following cervical SCI (Dale-Nagle et al., 2010; Fuller et al., 2003; Lovett-Barr et al., 2012; Vinit et al., 2009). More specifically, brief intermittent exposures to hypoxia (3-10 x 5 minute exposure alternating with air) during terminal electrophysiological recordings of the phrenic nerves in spinal intact (uninjured) adult rats results in a prolonged increase of phrenic nerve output, called phrenic long term facilitation (Fuller et al., 2000; Mitchell et al., 2001). Long term facilitation has most frequently been studied using this acute $\mathbb{I H}$ strategy. Chronic IH (repeated 5 min exposures over 12 hours) has been shown to elicit long term respiratory plasticity although this can be accompanied with deleterious side effects (hippocampal damage and cognitive impairment) (Navarrete-Opazo and Mitchell, 2014; Vinit et al., 2009). The respiratory plasticity elicited by $\mathrm{IH}$ led to the development of a daily, acute $\mathrm{IH}$ strategy that could be used in awake animals to 'train' respiratory activity and improve recovery 
following $\mathrm{SCl}$, but without the detrimental effects seen with chronic $\mathrm{IH}$. Starting one week post$\mathrm{C} 2 \mathrm{HX}$, daily acute $\mathrm{IH}(10 \times 5$ minutes exposures to $10 \%$ inhaled oxygen, daily for 5-7 days) has since been shown to promote recovery of phrenic motor output ipsilateral to injury and enhance ventilatory function post-injury (Lovett-Barr et al., 2012). It should be noted that daily acute IH does not appear to significantly alter ventilation in spinal intact animals (Lovett-Barr et al., 2012).

While serotonergic changes are known to contribute to the therapeutic effects (BakerHerman and Mitchell, 2002; Dale et al., 2014; Fuller et al., 2005), not all aspects of the anatomical underpinnings have been explored. For instance, the role of spinal interneurons in Long term facilitation remains unclear. Given its relative safety, $\mathrm{IH}$ therapy is now already being tested clinically for its ability to promote recovery of both respiratory (Tester et al., 2014) and non-respiratory (Dale et al., 2014; Hayes et al., 2014; Trumbower et al., 2012) motor functions. The therapeutic benefits of $\mathrm{IH}$ in improving non-respiratory function raises the question: is recovery enhanced by increasing respiratory drive and activity or via an alternative chemical stimulation induced by low oxygen levels? It is not clear whether intermittent increases in respiratory activity that are induced by other means (increased metabolic demands, exercise, hypercapnia) may elicit similar plasticity. However, the efficacy of this treatment has not been extensively tested following a more clinically-comparable model of $\mathrm{SCl}$, such as contusion injury.

While data from pre-clinical and clinical studies in non-respiratory systems support a more widespread beneficial effect following $\mathrm{IH}$, future work should also explore whether alternative training strategies (e.g. intermittent hypercapnia) could improve upon existing methods.

\section{Locomotor Training and Respiration post-SCI}

Treadmill training is perhaps the most extensively used locomotor training strategy in a range of animal injury models. While use of treadmill training (Figure 3F) has focused on improving locomotor function, it has also been shown to improve sensory (Detloff et al., 2014; Dugan and Sagen, 2014; Ward et al., 2014), bladder (Ward et al., 2014) and cardiovascular (Ditor et al., 2005a; Ditor et al., 2005b; Hicks and Ginis, 2008) function in injured animals and people. Recent clinical studies at the University of Louisville (Terson de Paleville et al., 2013) revealed that treadmill training can enhance respiratory recovery in people with cervical and thoracic injuries. Training began chronically following injury (12 - 48 months post-injury) and consisted of 60 minutes of assisted stepping on a treadmill (with body weight support), 5 days a week for an 
average of about 12 weeks, improving respiratory function and increasing respiratory muscle activity in 7 of the 8 subjects post-training.

The mechanisms underlying this exercise-induced respiratory plasticity remain unclear. Exercise-induced changes in respiratory musculature are the subject of ongoing research in uninjured animal models and people. As Terson de Paleville et al. note (Terson de Paleville et al., 2013), locomotor training as used in their study increases heart rate and minute-ventilation. Accordingly, they conclude that locomotor training intensity had to be sufficient to increase cardiopulmonary activity. Consistent with this conclusion are the results from a separate study that did not show improvement in cardiopulmonary function following robot-assisted stepping (in which the injured people remained 'passive' throughout training) (Jack et al., 2011). In contrast, however, several studies have revealed evidence for respiratory rhythm entrainment (Iscoe et al., 1976; Morin and Viala, 2002; Potts et al., 2005) and increases in phrenic motor output (Persegol et al., 1993; Waldrop et al., 1986a) following hindlimb stimulation. The possibility therefore exists that locomotion and stimulation of limb afferents may contribute to direct stimulation of respiratory circuitry and increased motor output. Support of this hypothesis is the reported example of locomotor-respiratory synchrony occurring following treadmill training in an individual with high (C1/2) incomplete SCI (Sherman et al., 2009). Locomotor-respiratory coupling has been demonstrated in a number of animal (see Figure 4) and human studies, although it is not known whether this phenomenon may serve as a therapeutic target post-SCI.

\section{Treatment Effect and Neuroplasticity}

The molecular and anatomical mechanisms of functional plasticity following activity-based therapies (ABTs) or neural interfaces (Nis) are a subject of ongoing research. Despite the differences in these treatment strategies, several similar anatomical and molecular changes are reported to occur that have been associated with the therapeutic effects seen. For example, as has been reviewed elsewhere (Houle and Cote, 2013), anatomical and molecular changes following ABTs include, but are not limited to i) increased spinal neuron activity, ii) increased expression of growth factors and iii) increased serotonergic input to spinal neurons and increased serotonergic receptor expression. To what extent these changes are comparable between $\mathrm{ABT}$ and $\mathrm{NI}$ strategies is presently unclear, and beyond the scope of this present review. A common theme among these therapeutic strategies, however, is the contribution of spinal interneurons to the modulation of motor and sensory activity during and following treatment. Spinal interneurons can alter the function and connectivity in response to ABTs and/or NIs (Harkema, 2008; Houle and Cote, 2013; van den Brand et al., 2012). 


\section{Spinal Interneurons}

With a rapidly growing appreciation for the neuroplastic reserve of the injured spinal cord in the past decade (Blesch and Tuszynski, 2009; Darian-Smith, 2009; Fouad and Tse, 2008; Harkema, 2001; Stein, 2008), spinal interneurons have been identified as a key component by contributing to neural circuit remodeling and modulation of motoneuron excitability (Alilain et al., 2011; Bareyre et al., 2004; Courtine et al., 2009; Courtine et al., 2008; Flynn et al., 2011; Harkema, 2008; Lane et al., 2009c; Lane et al., 2008; Sandhu et al., 2009; Stelzner and Cullen, 1991). In addition, increased interneuronal activity (Houle and Cote, 2013) and reorganization of connectivity (Rank et al., 2015) is also thought to be necessary for some of the functional benefits seen with locomotor training (Houle and Cote, 2013). While a similar role for interneurons may be a component of the plasticity induced by intermittent hypoxia, this has not yet been studied in depth. Thus far the focus has been primarily on changes at the level of the motoneuron pool. According to the conventional view, phrenic motoneurons receive primarily monosynaptic excitatory (inspiratory) and inhibitory (expiratory) inputs from supraspinal respiratory neurons located at the pontomedullary level. The role of spinal interneurons in phrenic activity and in shaping motor output has been largely overlooked. However, anatomical (Lane et al., 2009c; Lane et al., 2008; Yates et al., 1999), neuropharmacological (Marchenko et al., 2015), and electrophysiological (Bellingham, 1999; Bellingham and Lipski, 1990; Douse and Duffin, 1993; Duffin and Iscoe, 1996; Palisses et al., 1989; Palisses and Viala, 1987; Tian and Duffin, 1996) characterization of spinal phrenic interneurons in a number of species, has led to a growing appreciation for their involvement in recovery of phrenic motor activity after injury. Spinal interneurons are anatomically positioned to contribute to plasticity (Lane et al., 2008), and evidence suggests that they contribute to spontaneous phrenic recovery post-SCI (Buttry and Goshgarian, 2014; Sandhu et al., 2009). Ongoing research is beginning to focus more on how spinal interneurons may represent a therapeutic target for neural interfacing and/or activity based therapies.

\section{CLOSING REMARKS}

A vast range of therapeutic strategies exist for electrically or physically enhancing respiratory activity and plasticity following SCl. As new technologies develop for pre-clinical and translational neuroscience research (e.g. development of opto- and chemo-genetic methods and novel electrodes better suited to the spinal cord), new opportunities will exist for harnessing and enhancing neural activity. The genetic manipulation of neuronal populations to incorporate 
receptors that are activated only by specific wavelengths of light (channelrhodopsins, halorhodopsins) or designer receptors exclusively activated by designer drugs (a.k.a. DREADDs), has enabled researchers to control neuronal activity. Furthermore, these approaches can be less invasive than other neural interfacing strategies in use.

Promising treatments for improving respiratory function post-SCl are being tested and optimized pre-clinically with the goal of translation to clinical trial. New and ongoing clinical trials that test strategies to treat non-respiratory disorders (e.g. intraspinal microstimulation) will help to guide translation for the treatment of respiratory dysfunction. As advances in neural interfacing methods continue to expand and optimize treatment options, we predict that existing clinically used strategies will be readily modified (e.g. the development of closed-loop diaphragm pacing) and new treatment approaches will develop. As our understanding of the underlying neuroplastic mechanisms improves, treatments will be more effectively directed toward harnessing ongoing beneficial plasticity which will enhance lasting functional improvement. In addition to ongoing bench-to-bedside translation, current clinically used strategies are now being reverse-translated. Experimental modelling of clinically used therapies will enable more effective pre-clinical research and rapid improvement upon existing treatments. Ongoing bi-directional translation of this nature is necessary for the timely and effective development, translation and optimization of treatments for respiratory dysfunction in people with SCl.

It is widely appreciated that no single treatment will completely restore function to any motor or sensory system post-SCI. There is a growing consensus among many researchers and clinicians that promising treatments will likely be most effective when paired with rehabilitative approaches. Pre-clinical research has shown that combining NIs and ABTs with pharmacological treatment strategies can promote significant functional improvement post-SCI (van den Brand et al., 2012). As cellular therapies for SCI gain attention through translation to clinical trial (see also XXX in this issue), preclinical work has begun assessing combinatorial strategies for the use of these with ABTs or NI therapies to focus accompanying neuroplastic changes and enhance their therapeutic effect (Liu et al., 2013, 2014). As neural engineering advances and a wider array of tools emerges to target deficits and enhance directed plasticity, the options to improve function and restore controls after injury are expanding, and the likelihood of more effective SCI therapies increasing.

\section{ACKNOWLEDGMENTS}


Financial support was provided by the National Institute of Health (NIH), NINDS (R01-

NS081112; MAL), the United States Department of Defense (USAMRAH \#SC140038; VM), the Craig. H. Neilsen Foundation (Project 338432; MAL) and the Cure Paralysis Now foundation (TB). We thank Dr. Ralph Marino for his comments on the manuscript during preparation. 


\section{FIGURES}

Figure 1

A schematic diagram (A) of the cervical spinal cord (adapted from Lane 2011) shows the distribution of spinal phrenic motor- and interneurons (green) associated with one half of the diaphragm. The phrenic motoneuron pool innervates the hemi-diaphragm via the phrenic nerve. Spinal phrenic neurons receive bulbospinal respiratory related drive from cells in the ventral respiratory column (VRC, blue). Phrenic motor output is also modulated by serotonergic pathways (purple). Input from neurons in both the VRC and serotonergic nuclei have been shown to be essential for functional respiratory plasticity seen following $\mathrm{C} 2$ hemisection. Left and right hemidiaphragm electromyography (dEMG; B) reveal recovery of activity, albeit limited, ipsilateral (ipsi.) to injury (left-side) 12 weeks post-C2 hemisection. Contralateral (contra.) diaphragm activity is not impaired by the injury, but may increase to compensate for ipsilateral deficits. Asterisk indicates an 'augmented' breath, during which activity is increased bilaterally.

Figure 2

Contusive injury results in a combined white and grey matter lesion. As indicated in the schematic diagram (A), mid-cervical contusion injury compromises both descending axonal pathways and spinal phrenic motor- and interneurons. Terminal diaphragm EMG (dEMG) following lateralized contusion injury reveals ipsilateral diaphragm paresis during baseline breathing (breathing room air; B) and an attenuated response to hypoxic (not shown) or hypercapnic challenge (B). The increase in diaphragm activity seen with hypercapnic challenge is indicated by the blue bar in $\mathbf{B}$.

Figure 3.

Schematic diagram of strategies to drive neural activity using electrical stimuli (neural interfaces) and physical stimuli (activity-based therapies). Neural interfaces include strategies applied to the periphery such as functional electrical stimulation (FES) (diaphragm pacers (Ai), and limb FES (Aii)). Electrical stimuli can also be applied to the spinal cord via epidural stimulation (B) and intraspinal microstimulation (C) as well as supraspinally via transcranial magnetic stimulation (D). Activity-based therapies use physical stimuli to elicit increased respiratory drive and neural stimulation via strategies like resistance training (Ei) or intermittent 
hypoxia (Eii), as well as locomotor training accomplished with, for example, the use of a treadmill $(\mathbf{F})$.

Figure 4

Hindlimb muscle stimulation was shown to alter the pattern of phrenic motor output. Stimulation of the tibialis posterior (extensor) muscle was achieved via two silver electrodes inserted into the belly of the muscle $(1 \mathrm{~cm}$ apart) in a vagotomized, chemo/barro receptor denervated and paralyzed (Vecuronium) adult male rat under isoflurane anesthesia (1\% in oxygen). Tibialis stimulation (train pulses, $50 \mathrm{~Hz}, \mathrm{n}=30$, pulse duration $1 \mathrm{~ms}, 400 \mathrm{mkA}$ ) during terminal phrenic nerve recordings $(\mathbf{A})$ revealed coupling of phrenic motor activity to the stimulus at a $2: 1$ ratio within a minute of the first stimulus (B). These results highlight the potential for therapeutic modulation of phrenic motor output by stimulation of non-respiratory muscles.

Figure 5.

Spinal cord stimulation is capable of ventilating an animal even following complete transection of the spinal cord at the first cervical segment (C1). Ventilatory patterns and $\mathrm{CO} \%$ are shown prior to spinal cord injury in $\mathbf{A}$. Following a complete $\mathrm{C} 1$ transection, the animal in this experiment was maintained on mechanical (positive-pressure) ventilator support (B). Turning off the ventilator (indicated by blue bar in B) confirmed that the animal was not capable of maintaining ventilation. However, epidural stimulation of the ventrolateral spinal cord (C) restored ventilatory patterns and a tidal volume comparable to that seen prior to injury. These results support those from DiMarco and colleagues, indicating that epidural stimulation is a viable approach for maintaining ventilation. 


\section{REFERENCES:}

Alilain, W.J., Horn, K.P., Hu, H., Dick, T.E., Silver, J., 2011. Functional regeneration of respiratory pathways after spinal cord injury. Nature 475, 196-200.

Alshekhlee, A., Onders, R.P., Syed, T.U., Elmo, M., Katirji, B., 2008. Phrenic nerve conduction studies in spinal cord injury: applications for diaphragmatic pacing. Muscle \& nerve 38, 1546-1552.

Alvarez-Argote, S., Gransee, H.M., Mora, J.C., Stowe, J.M., Jorgenson, A.J., Sieck, G.C., Mantilla, C.B., 2016. The Impact of Midcervical Contusion Injury on Diaphragm Muscle Function. J Neurotrauma 33, 500-509.

Awad, B.I., Warren, P.M., Steinmetz, M.P., Alilain, W.J., 2013. The role of the crossed phrenic pathway after cervical contusion injury and a new model to evaluate therapeutic interventions. Exp Neurol 248, 398-405.

Baker-Herman, T.L., Mitchell, G.S., 2002. Phrenic long-term facilitation requires spinal serotonin receptor activation and protein synthesis. The Journal of neuroscience : the official journal of the Society for Neuroscience 22, 6239-6246.

Baldi, J.C., Jackson, R.D., Moraille, R., Mysiw, W.J., 1998. Muscle atrophy is prevented in patients with acute spinal cord injury using functional electrical stimulation. Spinal cord 36, 463-469.

Bamford, J.A., Mushahwar, V.K., 2011. Intraspinal microstimulation for the recovery of function following spinal cord injury. Prog Brain Res 194, 227-239.

Bamford, J.A., Putman, C.T., Mushahwar, V.K., 2011. Muscle plasticity in rat following spinal transection and chronic intraspinal microstimulation. IEEE Trans Neural Syst Rehabil Eng 19, 79-83.

Bamford, J.A., Todd, K.G., Mushahwar, V.K., 2010. The effects of intraspinal microstimulation on spinal cord tissue in the rat. Biomaterials 31, 5552-5563.

Bareyre, F.M., Kerschensteiner, M., Raineteau, O., Mettenleiter, T.C., Weinmann, O., Schwab, M.E., 2004. The injured spinal cord spontaneously forms a new intraspinal circuit in adult rats. Nat Neurosci 7 , 269-277.

Bass, C.R., Davis, M., Rafaels, K., Rountree, M.S., Harris, R.M., Sanderson, E., Andrefsky, W., DiMarco, G., Zielinski, M., 2005. A methodology for assessing blast protection in explosive ordnance disposal bomb suits. International journal of occupational safety and ergonomics : JOSE 11, 347-361.

Baussart, B., Stamegna, J.C., Polentes, J., Tadie, M., Gauthier, P., 2006. A new model of upper cervical spinal contusion inducing a persistent unilateral diaphragmatic deficit in the adult rat. Neurobiol Dis 22, 562-574.

Baydur, A., Sassoon, C.S.H., 2010. Respiratory Dysfunction in Spinal Cord Disorders, in: Lin, V.W. (Ed.), Spinal Cord Medicine: Principles and Practice, 2 ed. Demos Medical, New York, pp. 215-229.

Bell, S., Shaw-Dunn, J., Gollee, H., Allan, D.B., Fraser, M.H., McLean, A.N., 2007. Improving respiration in patients with tetraplegia by functional electrical stimulation: an anatomical perspective. Clin Anat 20, 689-693.

Bellingham, M.C., 1999. Synaptic inhibition of cat phrenic motoneurons by internal intercostal nerve stimulation. J Neurophysiol 82, 1224-1232.

Bellingham, M.C., Lipski, J., 1990. Respiratory interneurons in the C5 segment of the spinal cord of the cat. Brain Res 533, 141-146.

Bezdudnaya, T., Marchenko, V., Whelan, T.J., Lane, M.A., 2014. Supraspinal respiratory neuroplasticity within reticular nuclei following cervical spinal cord injury, Annual meeting of the Society for Neuroscience, Wahsington DC, USA.

Bezdudnaya, T., Melconian, M., Negron, K.M., Whelan, T.J., Marchenko, V., Lane, M.A., 2015. MUSCLE STIMULATION ENHANCES RESPIRATORY RECOVERY FOLLOWING CERVICAL SPINAL CORD INJURY, International Symposium on Neural Regeneration, Asilomar, Pacfific Grove, CA. 
Blesch, A., Tuszynski, M.H., 2009. Spinal cord injury: plasticity, regeneration and the challenge of translational drug development. Trends Neurosci 32, 41-47.

Bolser, D.C., Jefferson, S.C., Rose, M.J., Tester, N.J., Reier, P.J., Fuller, D.D., Davenport, P.W., Howland, D.R., 2009. Recovery of airway protective behaviors after spinal cord injury. Respir Physiol Neurobiol $169,150-156$.

Buttry, J.L., Goshgarian, H.G., 2014. Injection of WGA-Alexa 488 into the ipsilateral hemidiaphragm of acutely and chronically $\mathrm{C} 2$ hemisected rats reveals activity-dependent synaptic plasticity in the respiratory motor pathways. Exp Neurol 261, 440-450.

Choi, H., Liao, W.-L., Newton, K.M., Onario, R.C., King, A.M., Desilets, F.C., Woodard, E.J., Eichler, M.E., Frontera, W.R., Sabharwal, S., Teng, Y.D., 2005. Respiratory abnormalities resulting from midcervical spinal cord injury and their reversal by serotonin $1 \mathrm{~A}$ agonists in conscious rats. The Journal of neuroscience : the official journal of the Society for Neuroscience 25, 4550-4559.

Courtine, G., Gerasimenko, Y., van den Brand, R., Yew, A., Musienko, P., Zhong, H., Song, B., Ao, Y., Ichiyama, R.M., Lavrov, I., Roy, R.R., Sofroniew, M.V., Edgerton, V.R., 2009. Transformation of nonfunctional spinal circuits into functional states after the loss of brain input. Nat Neurosci 12, 13331342.

Courtine, G., Song, B., Roy, R.R., Zhong, H., Herrmann, J.E., Ao, Y., Qi, J., Edgerton, V.R., Sofroniew, M.V., 2008. Recovery of supraspinal control of stepping via indirect propriospinal relay connections after spinal cord injury. Nat Med 14, 69-74.

Creasey, G.H., Ho, C.H., Triolo, R.J., Gater, D.R., DiMarco, A.F., Bogie, K.M., Keith, M.W., 2004. Clinical applications of electrical stimulation after spinal cord injury. J Spinal Cord Med 27, 365-375.

Cuellar, J.M., Alataris, K., Walker, A., Yeomans, D.C., Antognini, J.F., 2013. Effect of high-frequency alternating current on spinal afferent nociceptive transmission. Neuromodulation 16, 318-327; discussion 327.

D'Orangeville, L., Cote, B., Houle, D., Morin, H., 2013. The effects of throughfall exclusion on xylogenesis of balsam fir. Tree physiology 33, 516-526.

Dalal, K., DiMarco, A.F., 2014. Diaphragmatic pacing in spinal cord injury. Phys Med Rehabil Clin N Am 25, 619-629, viii.

Dale-Nagle, E.A., Hoffman, M.S., MacFarlane, P.M., Satriotomo, I., Lovett-Barr, M.R., Vinit, S., Mitchell, G.S., 2010. Spinal plasticity following intermittent hypoxia: implications for spinal injury. Ann N Y Acad Sci 1198, 252-259.

Dale, E.A., Ben Mabrouk, F., Mitchell, G.S., 2014. Unexpected benefits of intermittent hypoxia: enhanced respiratory and nonrespiratory motor function. Physiology (Bethesda) 29, 39-48.

Darian-Smith, C., 2009. Synaptic plasticity, neurogenesis, and functional recovery after spinal cord injury. Neuroscientist 15, 149-165.

Darlot, F., Cayetanot, F., Gauthier, P., Matarazzo, V., Kastner, A., 2012. Extensive respiratory plasticity after cervical spinal cord injury in rats: axonal sprouting and rerouting of ventrolateral bulbospinal pathways. Exp Neurol 236, 88-102.

Davey, N.J., Murphy, K., Maskill, D.W., Guz, A., Ellaway, P.H., 1996. Site of facilitation of diaphragm EMG to corticospinal stimulation during inspiration. Respiration physiology 106, 127-135.

Detloff, M.R., Smith, E.J., Quiros Molina, D., Ganzer, P.D., Houle, J.D., 2014. Acute exercise prevents the development of neuropathic pain and the sprouting of non-peptidergic (GDNF- and artemin-responsive) c-fibers after spinal cord injury. Exp Neurol 255, 38-48.

DiMarco, A.F., 2001. Neural prostheses in the respiratory system. J Rehabil Res Dev 38, 601-607. DiMarco, A.F., 2005. Restoration of respiratory muscle function following spinal cord injury. Review of electrical and magnetic stimulation techniques. Respir Physiol Neurobiol 147, 273-287.

DiMarco, A.F., 2009. Phrenic nerve stimulation in patients with spinal cord injury. Respir Physiol Neurobiol 169, 200-209. 
DiMarco, A.F., Altose, M.D., Cropp, A., Durand, D., 1987. Activation of the inspiratory intercostal muscles by electrical stimulation of the spinal cord. Am Rev Respir Dis 136, 1385-1390.

DiMarco, A.F., Kowalski, K.E., 2009. High-frequency spinal cord stimulation of inspiratory muscles in dogs: a new method of inspiratory muscle pacing. J Appl Physiol (1985) 107, 662-669.

DiMarco, A.F., Kowalski, K.E., 2010. Intercostal muscle pacing with high frequency spinal cord stimulation in dogs. Respir Physiol Neurobiol 171, 218-224.

DiMarco, A.F., Kowalski, K.E., 2011. Distribution of electrical activation to the external intercostal muscles during high frequency spinal cord stimulation in dogs. J Physiol 589, 1383-1395.

Dimarco, A.F., Kowalski, K.E., 2013. Spinal pathways mediating phrenic activation during high frequency spinal cord stimulation. Respir Physiol Neurobiol 186, 1-6.

DiMarco, A.F., Kowalski, K.E., 2015. Electrical activation to the parasternal intercostal muscles during high-frequency spinal cord stimulation in dogs. J Appl Physiol (1985) 118, 148-155.

DiMarco, A.F., Onders, R.P., Ignagni, A., Kowalski, K.E., Mortimer, J.T., 2005a. Phrenic nerve pacing via intramuscular diaphragm electrodes in tetraplegic subjects. Chest 127, 671-678.

DiMarco, A.F., Onders, R.P., Kowalski, K.E., Miller, M.E., Ferek, S., Mortimer, J.T., 2002. Phrenic nerve pacing in a tetraplegic patient via intramuscular diaphragm electrodes. American journal of respiratory and critical care medicine 166, 1604-1606.

DiMarco, A.F., Supinski, G.S., Petro, J.A., Takaoka, Y., 1994. Evaluation of intercostal pacing to provide artificial ventilation in quadriplegics. Am J Respir Crit Care Med 150, 934-940.

DiMarco, A.F., Takaoka, Y., Kowalski, K.E., 2005b. Combined intercostal and diaphragm pacing to provide artificial ventilation in patients with tetraplegia. Arch Phys Med Rehabil 86, 1200-1207.

Dimitrijevic, M.M., Faganel, J., 1980. Evaluation of the effect of spinal cord stimulation on motor performance in patients with upper motor neurone lesions. Int J Rehabil Res 3, 565-566.

Ditor, D.S., Kamath, M.V., MacDonald, M.J., Bugaresti, J., McCartney, N., Hicks, A.L., 2005a. Effects of body weight-supported treadmill training on heart rate variability and blood pressure variability in individuals with spinal cord injury. J Appl Physiol (1985) 98, 1519-1525.

Ditor, D.S., Macdonald, M.J., Kamath, M.V., Bugaresti, J., Adams, M., McCartney, N., Hicks, A.L., 2005b. The effects of body-weight supported treadmill training on cardiovascular regulation in individuals with motor-complete SCl. Spinal Cord 43, 664-673.

Douse, M.A., Duffin, J., 1993. Axonal projections and synaptic connections of C5 segment expiratory interneurones in the cat. J Physiol 470, 431-444.

Duffin, J., Iscoe, S., 1996. The possible role of C5 segment inspiratory interneurons investigated by crosscorrelation with phrenic motoneurons in decerebrate cats. Exp Brain Res 112, 35-40.

Dugan, E., Sagen, J., 2014. An Intensive Locomotor Training Paradigm Improves Neuropathic Pain following Spinal Cord Compression Injury in Rats. J Neurotrauma.

Edgerton, V.R., Courtine, G., Gerasimenko, Y.P., Lavrov, I., Ichiyama, R.M., Fong, A.J., Cai, L.L., Otoshi, C.K., Tillakaratne, N.J., Burdick, J.W., Roy, R.R., 2008. Training locomotor networks. Brain Res Rev 57, 241-254.

Edgerton, V.R., Harkema, S., 2011. Epidural stimulation of the spinal cord in spinal cord injury: current status and future challenges. Expert Rev Neurother 11, 1351-1353.

El-Bohy, A.A., Schrimsher, G.W., Reier, P.J., Goshgarian, H.G., 1998. Quantitative assessment of respiratory function following contusion injury of the cervical spinal cord. Exp Neurol 150, 143-152.

Ellenberger, H.H., Feldman, J.L., 1988. Monosynaptic transmission of respiratory drive to phrenic motoneurons from brainstem bulbospinal neurons in rats. J Comp Neurol 269, 47-57.

Ellenberger, H.H., Feldman, J.L., Goshgarian, H.G., 1990. Ventral respiratory group projections to phrenic motoneurons: electron microscopic evidence for monosynaptic connections. The Journal of comparative neurology 302, 707-714. 
Flynn, J.R., Graham, B.A., Galea, M.P., Callister, R.J., 2011. The role of propriospinal interneurons in recovery from spinal cord injury. Neuropharmacology 60, 809-822.

Fouad, K., Tse, A., 2008. Adaptive changes in the injured spinal cord and their role in promoting functional recovery. Neurol Res 30, 17-27.

Fuller, D.D., Bach, K.B., Baker, T.L., Kinkead, R., Mitchell, G.S., 2000. Long term facilitation of phrenic motor output. Respir Physiol 121, 135-146.

Fuller, D.D., Baker-Herman, T.L., Golder, F.J., Doperalski, N.J., Watters, J.J., Mitchell, G.S., 2005. Cervical spinal cord injury upregulates ventral spinal 5-HT2A receptors. J Neurotrauma 22, 203-213.

Fuller, D.D., Doperalski, N.J., Dougherty, B.J., Sandhu, M.S., Bolser, D.C., Reier, P.J., 2008. Modest spontaneous recovery of ventilation following chronic high cervical hemisection in rats. Experimental neurology 211, 97-106.

Fuller, D.D., Johnson, S.M., Olson, E.B., Jr., Mitchell, G.S., 2003. Synaptic pathways to phrenic motoneurons are enhanced by chronic intermittent hypoxia after cervical spinal cord injury. The Journal of neuroscience : the official journal of the Society for Neuroscience 23, 2993-3000.

Galea, M.P., Dunlop, S.A., Davis, G.M., Nunn, A., Geraghty, T., Hsueh, Y.S., Churilov, L., 2013. Intensive exercise program after spinal cord injury ("Full-On"): study protocol for a randomized controlled trial.

Trials 14, 291.

Gariepy, J.F., Missaghi, K., Chevallier, S., Chartre, S., Robert, M., Auclair, F., Lund, J.P., Dubuc, R., 2012. Specific neural substrate linking respiration to locomotion. Proceedings of the National Academy of Sciences of the United States of America 109, E84-92.

Gariepy, J.F., Missaghi, K., Dubuc, R., 2010. The interactions between locomotion and respiration. Progress in brain research 187, 173-188.

Giangregorio, L., McCartney, N., 2006. Bone loss and muscle atrophy in spinal cord injury: epidemiology, fracture prediction, and rehabilitation strategies. The journal of spinal cord medicine 29, 489-500. Giszter, S.F., 2015. Spinal primitives and intra-spinal micro-stimulation (ISMS) based prostheses: a neurobiological perspective on the "known unknowns" in ISMS and future prospects. Front Neurosci 9, 72.

Golder, F.J., Fuller, D.D., Lovett-Barr, M.R., Vinit, S., Resnick, D.K., Mitchell, G.S., 2011. Breathing patterns after mid-cervical spinal contusion in rats. Exp Neurol 231, 97-103.

Golder, F.J., Mitchell, G.S., 2005. Spinal synaptic enhancement with acute intermittent hypoxia improves respiratory function after chronic cervical spinal cord injury. The Journal of neuroscience : the official journal of the Society for Neuroscience 25, 2925-2932.

Golder, F.J., Reier, P.J., Bolser, D.C., 2001. Altered respiratory motor drive after spinal cord injury: supraspinal and bilateral effects of a unilateral lesion. The Journal of neuroscience : the official journal of the Society for Neuroscience 21, 8680-8689.

Gonzalez-Bermejo, J., C, L.L., Similowski, T., Morelot-Panzini, C., 2015. Respiratory neuromodulation in patients with neurological pathologies: for whom and how? Ann Phys Rehabil Med 58, 238-244.

Goshgarian, H., 2003a. The crossed phrenic phenomenon: a model for plasticity in the respiratory pathways following spinal cord injury. J Appl Physiol 94, 795-810.

Goshgarian, H.G., 2003b. The crossed phrenic phenomenon: a model for plasticity in the respiratory pathways following spinal cord injury. J Appl Physiol 94, 795-810.

Goshgarian, H.G., 2009. The crossed phrenic phenomenon and recovery of function following spinal cord injury. Respir Physiol Neurobiol 169, 85-93.

Goshgarian, H.G., Ellenberger, H.H., Feldman, J.L., 1991. Decussation of bulbospinal respiratory axons at the level of the phrenic nuclei in adult rats: a possible substrate for the crossed phrenic phenomenon. Exp Neurol 111, 135-139. 
Hajela, N., Mummidisetty, C.K., Smith, A.C., Knikou, M., 2013. Corticospinal reorganization after locomotor training in a person with motor incomplete paraplegia. BioMed research international 2013, 516427.

Hammond, C.S., Gaeta, H., Sapienza, C., Davenport, P.W., 1999. Respiratory-related evoked potential elicited by expiratory occlusion. J Appl Physiol (1985) 87, 835-842.

Harkema, S., Gerasimenko, Y., Hodes, J., Burdick, J., Angeli, C., Chen, Y., Ferreira, C., Willhite, A., Rejc, E., Grossman, R.G., Edgerton, V.R., 2011. Effect of epidural stimulation of the lumbosacral spinal cord on voluntary movement, standing, and assisted stepping after motor complete paraplegia: a case study. Lancet 377, 1938-1947.

Harkema, S.J., 2001. Neural plasticity after human spinal cord injury: application of locomotor training to the rehabilitation of walking. Neuroscientist 7, 455-468.

Harkema, S.J., 2008. Plasticity of interneuronal networks of the functionally isolated human spinal cord. Brain Res Rev 57, 255-264.

Hayes, H.B., Jayaraman, A., Herrmann, M., Mitchell, G.S., Rymer, W.Z., Trumbower, R.D., 2014. Daily intermittent hypoxia enhances walking after chronic spinal cord injury: A randomized trial. Neurology 82, 104-113.

Hicks, A.L., Ginis, K.A., 2008. Treadmill training after spinal cord injury: it's not just about the walking. J Rehabil Res Dev 45, 241-248.

Hill, J.M., Adreani, C.M., Kaufman, M.P., 1996. Muscle reflex stimulates sympathetic postganglionic efferents innervating triceps surae muscles of cats. The American journal of physiology 271, H38-43. Hillen, B.K., Abbas, J.J., Jung, R., 2013. Accelerating locomotor recovery after incomplete spinal injury. Annals of the New York Academy of Sciences 1279, 164-174.

Ho, C.H., Triolo, R.J., Elias, A.L., Kilgore, K.L., DiMarco, A.F., Bogie, K., Vette, A.H., Audu, M.L., Kobetic, R., Chang, S.R., Chan, K.M., Dukelow, S., Bourbeau, D.J., Brose, S.W., Gustafson, K.J., Kiss, Z.H., Mushahwar, V.K., 2014. Functional electrical stimulation and spinal cord injury. Phys Med Rehabil Clin N Am 25, 631654, ix.

Hoh, D.J., Mercier, L.M., Hussey, S.P., Lane, M.A., 2013. Respiration following spinal cord injury: evidence for human neuroplasticity. Respir Physiol Neurobiol 189, 450-464.

Houle, J.D., Cote, M.P., 2013. Axon regeneration and exercise-dependent plasticity after spinal cord injury. Annals of the New York Academy of Sciences 1279, 154-163.

Hsieh, F.H., Giszter, S.F., 2011. Robot-driven spinal epidural stimulation compared with conventional stimulation in adult spinalized rats. Conf Proc IEEE Eng Med Biol Soc 2011, 5807-5810.

Hubli, M., Dietz, V., 2013. The physiological basis of neurorehabilitation--locomotor training after spinal cord injury. Journal of neuroengineering and rehabilitation 10, 5.

Ichiyama, R.M., Courtine, G., Gerasimenko, Y.P., Yang, G.J., van den Brand, R., Lavrov, I.A., Zhong, H., Roy, R.R., Edgerton, V.R., 2008. Step training reinforces specific spinal locomotor circuitry in adult spinal rats. The Journal of neuroscience : the official journal of the Society for Neuroscience 28, 7370-7375. Isaev, G.G., Gerasimenko, Y.P., Selionov, V.A., Kartashova, N.A., 2004. Respiratory responses to voluntary and reflexly-induced stepping movements in normal subjects and spinal patients. J Physiol Pharmacol 55 Suppl 3, 77-82.

Iscoe, S., Dankoff, J., Migicovsky, R., Polosa, C., 1976. Recruitment and discharge frequency of phrenic motoneurones during inspiration. Respiration physiology 26, 113-128.

Iscoe, S., Polosa, C., 1976. Synchronization of respiratory frequency by somatic afferent stimulation. J Appl Physiol 40, 138-148.

Jack, L.P., Purcell, M., Allan, D.B., Hunt, K.J., 2011. The metabolic cost of passive walking during roboticsassisted treadmill exercise. Technol Health Care 19, 21-27.

Jarosz, R., Littlepage, M.M., Creasey, G., McKenna, S.L., 2012. Functional electrical stimulation in spinal cord injury respiratory care. Topics in spinal cord injury rehabilitation 18, 315-321. 
Kasten, M.R., Sunshine, M.D., Secrist, E.S., Horner, P.J., Moritz, C.T., 2013. Therapeutic intraspinal microstimulation improves forelimb function after cervical contusion injury. J Neural Eng 10, 044001. Keomani, E., Deramaudt, T.B., Petitjean, M., Bonay, M., Lofaso, F., Vinit, S., 2014. A murine model of cervical spinal cord injury to study post-lesional respiratory neuroplasticity. J Vis Exp.

Khedr, E.M., Trakhan, M.N., 2001. Localization of diaphragm motor cortical representation and determination of corticodiaphragmatic latencies by using magnetic stimulation in normal adult human subjects. Eur J Appl Physiol 85, 560-566.

Kowalski, K.E., Hsieh, Y.H., Dick, T.E., DiMarco, A.F., 2013. Diaphragm activation via high frequency spinal cord stimulation in a rodent model of spinal cord injury. Exp Neurol 247, 689-693.

Laciuga, H., Rosenbek, J.C., Davenport, P.W., Sapienza, C.M., 2014. Functional outcomes associated with expiratory muscle strength training: narrative review. J Rehabil Res Dev 51, 535-546.

Lane, M.A., 2011. Spinal respiratory motoneurons and interneurons. Respir Physiol Neurobiol 179, 3-13. Lane, M.A., Jones, A.L., O'Steen, B.E., Hunsaker, F.L., Vavrousek, J., Salazar, K., Fuller, D.D., Reier, P.J., 2009a. Pre-phrenic interneurons as an anatomical substrate for plasticity following cervical spinal cord injury (SCI) in the adult rat, Faseb J, p. 834.835.

Lane, M.A., Lee, K.Z., Fuller, D.D., Reier, P.J., 2009b. Spinal circuitry and respiratory recovery following spinal cord injury. Respir Physiol Neurobiol.

Lane, M.A., Lee, K.Z., Fuller, D.D., Reier, P.J., 2009c. Spinal circuitry and respiratory recovery following spinal cord injury. Respir Physiol Neurobiol 169, 123-132.

Lane, M.A., Lee, K.Z., Salazar, K., O'Steen, B.E., Bloom, D.C., Fuller, D.D., Reier, P.J., 2012. Respiratory function following bilateral mid-cervical contusion injury in the adult rat. Exp Neurol 235, 197-210. Lane, M.A., White, T.E., Coutts, M.A., Jones, A.L., Sandhu, M.S., Bloom, D.C., Bolser, D.C., Yates, B.J., Fuller, D.D., Reier, P.J., 2008. Cervical prephrenic interneurons in the normal and lesioned spinal cord of the adult rat. The Journal of comparative neurology 511, 692-709.

Lavrov, I., Gerasimenko, Y.P., Ichiyama, R.M., Courtine, G., Zhong, H., Roy, R.R., Edgerton, V.R., 2006. Plasticity of spinal cord reflexes after a complete transection in adult rats: relationship to stepping ability. J Neurophysiol 96, 1699-1710.

Lewis, L.J., Brookhart, J.M., 1951. Significance of the crossed phrenic phenomenon. Am J Physiol 166, 241-254.

Lissens, M.A., Vanderstraeten, G.G., 1996. Motor evoked potentials of the respiratory muscles in tetraplegic patients. Spinal Cord 34, 673-678.

Liu, Y., Grumbles, R.M., Thomas, C.K., 2013. Electrical stimulation of embryonic neurons for 1 hour improves axon regeneration and the number of reinnervated muscles that function. J Neuropathol Exp Neurol 72, 697-707.

Liu, Y., Grumbles, R.M., Thomas, C.K., 2014. Electrical stimulation of transplanted motoneurons improves motor unit formation. J Neurophysiol 112, 660-670.

Lovett-Barr, M.R., Satriotomo, I., Muir, G.D., Wilkerson, J.E., Hoffman, M.S., Vinit, S., Mitchell, G.S., 2012. Repetitive intermittent hypoxia induces respiratory and somatic motor recovery after chronic cervical spinal injury. The Journal of neuroscience : the official journal of the Society for Neuroscience 32, 35913600.

Mantilla, C.B., Sieck, G.C., 2009. Neuromuscular adaptations to respiratory muscle inactivity. Respir Physiol Neurobiol 169, 133-140.

Marchenko, V., Ghali, M.G., Rogers, R.F., 2015. The role of spinal GABAergic circuits in the control of phrenic nerve motor output. Am J Physiol Regul Integr Comp Physiol 308, R916-926.

Martin, A.D., Smith, B.K., Davenport, P.D., Harman, E., Gonzalez-Rothi, R.J., Baz, M., Layon, A.J., Banner, M.J., Caruso, L.J., Deoghare, H., Huang, T.T., Gabrielli, A., 2011. Inspiratory muscle strength training improves weaning outcome in failure to wean patients: a randomized trial. Crit Care 15, R84. 
Martinez, M., Delivet-Mongrain, H., Rossignol, S., 2013. Treadmill training promotes spinal changes leading to locomotor recovery after partial spinal cord injury in cats. Journal of neurophysiology 109, 2909-2922.

Mateika, J.H., Duffin, J., 1995. A review of the control of breathing during exercise. European journal of applied physiology and occupational physiology 71, 1-27.

McBain, R.A., Boswell-Ruys, C.L., Lee, B.B., Gandevia, S.C., Butler, J.E., 2013. Abdominal muscle training can enhance cough after spinal cord injury. Neurorehabil Neural Repair 27, 834-843.

McBain, R.A., Boswell-Ruys, C.L., Lee, B.B., Gandevia, S.C., Butler, J.E., 2015. Electrical stimulation of abdominal muscles to produce cough in spinal cord injury: effect of stimulus intensity. Neurorehabil Neural Repair 29, 362-369.

McCloskey, D.I., Mitchell, J.H., 1972. Reflex cardiovascular and respiratory responses originating in exercising muscle. The Journal of physiology 224, 173-186.

Mercier, L.M., Gonzalez-Rothi, E.J., Streeter, K.A., Poirer, A.S., Reier, P.J., Fuller, D.D., Baekey, D.M., 2016. Instraspinal microstimulation and diaphragm activation following acute cervical spinal cord injury. Journal of Neurophysiology In Review.

Mitchell, G.S., Baker, T.L., Nanda, S.A., Fuller, D.D., Zabka, A.G., Hodgeman, B.A., Bavis, R.W., Mack, K.J., Olson, E.B., Jr., 2001. Invited review: Intermittent hypoxia and respiratory plasticity. J Appl Physiol (1985) 90, 2466-2475.

Mitchell, G.S., Johnson, S.M., 2003. Neuroplasticity in respiratory motor control. J Appl Physiol (1985) 94, 358-374.

Morawietz, C., Moffat, F., 2013. Effects of locomotor training after incomplete spinal cord injury: a systematic review. Archives of physical medicine and rehabilitation 94, 2297-2308.

Moreno, D.E., Yu, X.J., Goshgarian, H.G., 1992. Identification of the axon pathways which mediate functional recovery of a paralyzed hemidiaphragm following spinal cord hemisection in the adult rat. Exp Neurol 116, 219-228.

Morin, D., Viala, D., 2002. Coordinations of locomotor and respiratory rhythms in vitro are critically dependent on hindlimb sensory inputs. The Journal of neuroscience : the official journal of the Society for Neuroscience 22, 4756-4765.

Moritz, C.T., Lucas, T.H., Perlmutter, S.I., Fetz, E.E., 2007. Forelimb movements and muscle responses evoked by microstimulation of cervical spinal cord in sedated monkeys. J Neurophysiol 97, 110-120. Nantwi, K.D., El-Bohy, A.A., Schrimsher, G.W., Reier, P.J., Goshgarian, H., 1999. Spontaneous Functional Recovery in a Paralyzed Hemidiaphragm Following Upper Cervical Spinal Cord Injury in Adult Rats. Neurorehab Neural Repair 13, 225-234.

Navarrete-Opazo, A., Mitchell, G.S., 2014. Therapeutic potential of intermittent hypoxia: a matter of dose. Am J Physiol Regul Integr Comp Physiol 307, R1181-1197.

Nicaise, C., Frank, D.M., Hala, T.J., Authelet, M., Pochet, R., Adriaens, D., Brion, J.P., Wright, M.C., Lepore, A.C., 2013. Early phrenic motor neuron loss and transient respiratory abnormalities after unilateral cervical spinal cord contusion. J Neurotrauma 30, 1092-1099.

Nicaise, C., Hala, T.J., Frank, D.M., Parker, J.L., Authelet, M., Leroy, K., Brion, J.P., Wright, M.C., Lepore, A.C., 2012a. Phrenic motor neuron degeneration compromises phrenic axonal circuitry and diaphragm activity in a unilateral cervical contusion model of spinal cord injury. Exp Neurol 235, 539-552.

Nicaise, C., Putatunda, R., Hala, T.J., Regan, K.A., Frank, D.M., Brion, J.P., Leroy, K., Pochet, R., Wright, M.C., Lepore, A.C., 2012b. Degeneration of phrenic motor neurons induces long-term diaphragm deficits following mid-cervical spinal contusion in mice. J Neurotrauma 29, 2748-2760.

O'Hara, T.E., Jr., Goshgarian, H.G., 1991. Quantitative assessment of phrenic nerve functional recovery mediated by the crossed phrenic reflex at various time intervals after spinal cord injury. Exp Neurol 111, 244-250. 
Onders, R.P., 2012. Functional electrical stimulation: restoration of respiratory function. Handbook of clinical neurology 109, 275-282.

Onders, R.P., Elmo, M., Kaplan, C., Katirji, B., Schilz, R., 2014. Extended use of diaphragm pacing in patients with unilateral or bilateral diaphragm dysfunction: a new therapeutic option. Surgery 156, 776784.

Onders, R.P., Elmo, M.J., Ignagni, A.R., 2007. Diaphragm pacing stimulation system for tetraplegia in individuals injured during childhood or adolescence. The journal of spinal cord medicine 30 Suppl 1, S2529.

Onders, R.P., Khansarinia, S., Weiser, T., Chin, C., Hungness, E., Soper, N., Dehoyos, A., Cole, T., Ducko, C., 2010. Multicenter analysis of diaphragm pacing in tetraplegics with cardiac pacemakers: positive implications for ventilator weaning in intensive care units. Surgery 148, 893-897; discussion 897-898. Onders, R.P., Ponsky, T.A., Elmo, M., Lidsky, K., Barksdale, E., 2011. First reported experience with intramuscular diaphragm pacing in replacing positive pressure mechanical ventilators in children. Journal of pediatric surgery $46,72-76$.

Oza, C.S., Giszter, S.F., 2014. Plasticity and alterations of trunk motor cortex following spinal cord injury and non-stepping robot and treadmill training. Exp Neurol 256, 57-69.

Oza, C.S., Giszter, S.F., 2015. Trunk robot rehabilitation training with active stepping reorganizes and enriches trunk motor cortex representations in spinal transected rats. The Journal of neuroscience : the official journal of the Society for Neuroscience 35, 7174-7189.

Palisses, R., Persegol, L., Viala, D., 1989. Evidence for respiratory interneurones in the C3-C5 cervical spinal cord in the decorticate rabbit. Experimental brain research 78, 624-632.

Palisses, R., Persegol, L., Viala, D., Viala, G., 1988. Reflex modulation of phrenic activity through hindlimb passive motion in decorticate and spinal rabbit preparation. Neuroscience 24, 719-728.

Palisses, R., Viala, D., 1987. [Existence of respiratory interneurons in the cervical spinal cord of the rabbit]. C R Acad Sci III 305, 321-324.

Persegol, L., Palisses, R., Viala, D., 1993. Characterization of hindlimb muscle afferents involved in ventilatory effects observed in decerebrate and spinal preparations. Experimental brain research 92, 495-501.

Porter, W.T., 1895. The path of the respiratory impulse from the bulb to the phrenic nuclei. Journal of Physiology 17, 455-485.

Posluszny, J.A., Jr., Onders, R., Kerwin, A.J., Weinstein, M.S., Stein, D.M., Knight, J., Lottenberg, L., Cheatham, M.L., Khansarinia, S., Dayal, S., Byers, P.M., Diebel, L., 2014. Multicenter review of diaphragm pacing in spinal cord injury: successful not only in weaning from ventilators but also in bridging to independent respiration. The journal of trauma and acute care surgery 76, 303-309; discussion 309-310. Potts, J.T., Rybak, I.A., Paton, J.F., 2005. Respiratory rhythm entrainment by somatic afferent stimulation. The Journal of neuroscience : the official journal of the Society for Neuroscience 25, 19651978.

Powers, S.K., Kavazis, A.N., Levine, S., 2009. Prolonged mechanical ventilation alters diaphragmatic structure and function. Critical care medicine 37, S347-353.

Raineteau, O., Schwab, M.E., 2001. Plasticity of motor systems after incomplete spinal cord injury. Nat Rev Neurosci 2, 263-273.

Ranck, J.B., Jr., 1975. Which elements are excited in electrical stimulation of mammalian central nervous system: a review. Brain Res 98, 417-440.

Rank, M.M., Flynn, J.R., Battistuzzo, C.R., Galea, M.P., Callister, R., Callister, R.J., 2015. Functional changes in deep dorsal horn interneurons following spinal cord injury are enhanced with different durations of exercise training. J Physiol 593, 331-345.

Sandhu, M.S., Dougherty, B.J., Lane, M.A., Bolser, D.C., Kirkwood, P.A., Reier, P.J., Fuller, D.D., 2009. Respiratory recovery following high cervical hemisection. Respir Physiol Neurobiol 169, 94-101. 
Sapienza, C., Troche, M., Pitts, T., Davenport, P., 2011. Respiratory strength training: concept and intervention outcomes. Semin Speech Lang 32, 21-30.

Sapienza, C.M., Wheeler, K., 2006. Respiratory muscle strength training: functional outcomes versus plasticity. Semin Speech Lang 27, 236-244.

Shealy, C.N., Mortimer, J.T., Reswick, J.B., 1967. Electrical inhibition of pain by stimulation of the dorsal columns: preliminary clinical report. Anesth Analg 46, 489-491.

Sherman, M.F., Lam, T., Sheel, A.W., 2009. Locomotor-respiratory synchronization after body weight supported treadmill training in incomplete tetraplegia: a case report. Spinal Cord 47, 896-898.

Sherwood, A.M., Sharkey, P.C., Dimitrijevic, M.R., 1980. Biomedical engineering specifications for epidural spinal cord stimulation to augment motor performance. Int Rehabil Med 2, 62-67.

Singh, A., Balasubramanian, S., Murray, M., Lemay, M., Houle, J., 2011a. Role of spared pathways in locomotor recovery after body-weight-supported treadmill training in contused rats. J Neurotrauma 28, 2405-2416.

Singh, A., Murray, M., Houle, J.D., 2011b. A training paradigm to enhance motor recovery in contused rats: effects of staircase training. Neurorehabil Neural Repair 25, 24-34.

Stein, R.B., 2008. The plasticity of the adult spinal cord continues to surprise. J Physiol 586, 2823.

Stelzner, D.J., Cullen, J.M., 1991. Do propriospinal projections contribute to hindlimb recovery when all long tracts are cut in neonatal or weanling rats? Exp Neurol 114, 193-205.

Sunshine, M.D., Cho, F.S., Lockwood, D.R., Fechko, A.S., Kasten, M.R., Moritz, C.T., 2013. Cervical intraspinal microstimulation evokes robust forelimb movements before and after injury. J Neural Eng 10, 036001.

Tator, C.H., Minassian, K., Mushahwar, V.K., 2012. Spinal cord stimulation: therapeutic benefits and movement generation after spinal cord injury. Handb Clin Neurol 109, 283-296.

Tedde, M.L., Onders, R.P., Teixeira, M.J., Lage, S.G., Ballester, G., Brotto, M.W., Okumura, E.M., Jatene, F.B., 2012. Electric ventilation: indications for and technical aspects of diaphragm pacing stimulation surgical implantation. Jornal brasileiro de pneumologia : publicacao oficial da Sociedade Brasileira de Pneumologia e Tisilogia 38, 566-572.

Terson de Paleville, D., McKay, W., Aslan, S., Folz, R., Sayenko, D., Ovechkin, A., 2013. Locomotor step training with body weight support improves respiratory motor function in individuals with chronic spinal cord injury. Respiratory physiology \& neurobiology 189, 491-497.

Tester, N.J., Fuller, D.D., Fromm, J.S., Spiess, M.R., Behrman, A.L., Mateika, J.H., 2014. Long-term facilitation of ventilation in humans with chronic spinal cord injury. American journal of respiratory and critical care medicine 189, 57-65.

Tian, G.F., Duffin, J., 1996. Connections from upper cervical inspiratory neurons to phrenic and intercostal motoneurons studied with cross-correlation in the decerebrate rat. Experimental brain research 110, 196-204.

Tibes, U., 1977. Reflex inputs to the cardiovascular and respiratory centers from dynamically working canine muscles. Some evidence for involvement of group III or IV nerve fibers. Circulation research 41, 332-341.

Trumbower, R.D., Jayaraman, A., Mitchell, G.S., Rymer, W.Z., 2012. Exposure to acute intermittent hypoxia augments somatic motor function in humans with incomplete spinal cord injury. Neurorehabil Neural Repair 26, 163-172.

van den Brand, R., Heutschi, J., Barraud, Q., DiGiovanna, J., Bartholdi, K., Huerlimann, M., Friedli, L., Vollenweider, I., Moraud, E.M., Duis, S., Dominici, N., Micera, S., Musienko, P., Courtine, G., 2012. Restoring voluntary control of locomotion after paralyzing spinal cord injury. Science 336, 1182-1185. Viala, D., Persegol, L., Palisses, R., 1987. Relationship between phrenic and hindlimb extensor activities during fictive locomotion. Neurosci Lett 74, 49-52. 
Vinit, S., Boulenguez, P., Efthimiadi, L., Stamegna, J.C., Gauthier, P., Kastner, A., 2005. Axotomized bulbospinal neurons express c-Jun after cervical spinal cord injury. Neuroreport 16, 1535-1539. Vinit, S., Gauthier, P., Stamegna, J.C., Kastner, A., 2006. High cervical lateral spinal cord injury results in long-term ipsilateral hemidiaphragm paralysis. J Neurotrauma 23, 1137-1146.

Vinit, S., Kastner, A., 2009a. Descending bulbospinal pathways and recovery of respiratory motor function following $\mathrm{SCl}$. Respir Physiol Neurobiol.

Vinit, S., Kastner, A., 2009b. Descending bulbospinal pathways and recovery of respiratory motor function following spinal cord injury. Respir Physiol Neurobiol 169, 115-122.

Vinit, S., Keomani, E., Deramaudt, T.B., Bonay, M., Petitjean, M., 2016. Reorganization of Respiratory Descending Pathways following Cervical Spinal Partial Section Investigated by Transcranial Magnetic Stimulation in the Rat. PLoS One 11, e0148180.

Vinit, S., Keomani, E., Deramaudt, T.B., Spruance, V.M., Bezdudnaya, T., Lane, M.A., Bonay, M., Petitjean, M., 2014. Interdisciplinary approaches of transcranial magnetic stimulation applied to a respiratory neuronal circuitry model. PLoS One 9, e113251.

Vinit, S., Lovett-Barr, M.R., Mitchell, G.S., 2009. Intermittent hypoxia induces functional recovery following cervical spinal injury. Respir Physiol Neurobiol 169, 210-217.

Waldrop, T.G., Henderson, M.C., Iwamoto, G.A., Mitchell, J.H., 1986a. Regional blood flow responses to stimulation of the subthalamic locomotor region. Respiration physiology 64, 93-102.

Waldrop, T.G., Mullins, D.C., Millhorn, D.E., 1986b. Control of respiration by the hypothalamus and by feedback from contracting muscles in cats. Respiration physiology 64, 317-328.

Ward, P.J., Herrity, A.N., Smith, R.R., Willhite, A., Harrison, B.J., Petruska, J.C., Harkema, S.J., Hubscher, C.H., 2014. Novel multi-system functional gains via task specific training in spinal cord injured male rats. J Neurotrauma 31, 819-833.

Warren, P.M., Alilain, W.J., 2014. The challenges of respiratory motor system recovery following cervical spinal cord injury. Progress in brain research 212, 173-220.

Wenger, N., Moraud, E.M., Gandar, J., Musienko, P., Capogrosso, M., Baud, L., Le Goff, C.G., Barraud, Q., Pavlova, N., Dominici, N., Minev, I.R., Asboth, L., Hirsch, A., Duis, S., Kreider, J., Mortera, A., Haverbeck, O., Kraus, S., Schmitz, F., DiGiovanna, J., van den Brand, R., Bloch, J., Detemple, P., Lacour, S.P., Bezard, E., Micera, S., Courtine, G., 2016. Spatiotemporal neuromodulation therapies engaging muscle synergies improve motor control after spinal cord injury. Nat Med 22, 138-145.

Wilkerson, J.E., Mitchell, G.S., 2009. Daily intermittent hypoxia augments spinal BDNF levels, ERK phosphorylation and respiratory long-term facilitation. Exp Neurol 217, 116-123.

Yates, B.J., Smail, J.A., Stocker, S.D., Card, J.P., 1999. Transneuronal tracing of neural pathways controlling activity of diaphragm motoneurons in the ferret. Neuroscience 90, 1501-1513. 